\title{
Mapping regional cortical bone responses to local changes in loading and systemic stimuli
}

\author{
Sara Windahl,"\#,", Peter J Delisser², Gabriel L Galea ${ }^{3,4, *}$
}

${ }^{1}$ Department of Laboratory Medicine, Division of Pathology, Karolinska University Hospital, Karolinska Institutet, Huddinge, Sweden. ${ }^{2}$ Veterinary Specialist Services, Brisbane, Australia. ${ }^{3}$ Developmental Biology and Cancer, UCL GOS Institute of Child Health, London.

${ }^{4}$ Comparative Biomedical Sciences, Royal Veterinary College, London

* Both authors contributed equally to this work

\# Corresponding Author:

Sara Windahl, Associate Professor, PhD

Department of Laboratory Medicine, Division of Pathology

Karolinska Institutet

F46, Karolinska University Hospital

14186 Huddinge

Sweden

Phone: +46-8-524 84624

E-mail: sara.windahl@ki.se

Key words: Mechanical loading, micro-computed tomography, Site Specificity 


\section{Abstract}

Quantification of cortical bone mass and architecture using $\mu \mathrm{CT}$ is commonplace in osteoporosis and osteoarthritis research. Different groups often report substantially divergent mouse cortical bone responses to nominally comparable interventions. In the case of studies assessing bones' responses to externally applied loading, these differences are commonly associated with methodological differences in the loading regime. This chapter describes a widely published, standardised method of in vivo mouse tibia axial loading to produce lamellar bone formation. Nonetheless, despite uniform application of axial loading, changes in bone mass are highly sitespecific within individual bones. For example, the mouse proximal tibia rapidly accrues new bone following axial loading, but this osteogenic response tapers to produce undetectable differences distally. Consequently, the selection of bone sites to perform comparisons at substantially influences the magnitude of differences observed. Application of the freely available Site Specificity software allows site-specific responses to be identified by rapidly quantifying cortical bone mass at each $1 \%$ site along the bone's length. This high-content screening tool has been informatively applied to study the local effects of changes in loading as well as systemic interventions including hormonal treatment and ageing. Automated multi-site analyses of cortical mass is increasingly identifying site-specific effects of "systemic" interventions such as global gene deletions. Biological mechanisms underlying this apparent regionalisation of cortical responses are largely unknown but may start to be elucidated by increasingly widespread application of Site Specificity methods. 


\section{Introduction}

Mechanical loading is the primary functional determinant of bone mass and architecture. Increases in loading-engendered mechanical strain locally trigger new bone formation, whereas reduced loading during disuse favours resorption (Hillam and Skerry, 1995). The resulting mechano-adaptive feedback loop, called the Mechanostat, locally adapts bone mass to its loadbearing function (Skerry, 2006). Mechanisms underlying the Mechanostat have largely been elucidated through the application of in vivo loading models to the bones of various vertebrates (Meakin et al., 2014b). Axial loading of the mouse tibia is now the most commonly applied in vivo loading model. Within the loaded bone, osteocytes and osteoblasts rapidly respond through wide-ranging transcriptomic changes (Galea et al., 2017), increased osteoblast and osteocyte metabolic activity (Hillam and Skerry, 1995, Skerry et al., 1989), and predictable downregulation of the anti-osteogenic Wnt antagonist sclerostin (Robling et al., 2008, Moustafa et al., 2012). However, the resulting loading-induced changes in cortical bone mass reported by different groups vary markedly. Some of these differences can be attributed to methodological changes such as insertion of rest periods, different waveforms, or studying mice of different ages (Meakin et al., 2014b).

Here we describe a widely-published, standardised method of in vivo mouse tibia axial loading to produce lamellar bone formation (Lionikaite et al., 2019, Bergstrom et al., 2018, Meakin et al., 2017, Svensson et al., 2016), Windahl et al 2013). Prior to performing in vivo loading it is essential to measure the strength of cadaveric bones in order to calculate peak loads which need to be applied to generate comparable strains between experimental groups. In wildtype mice, the change in cortical bone mass following loading is linearly related to peak strain when habitual loading is eliminated (Sugiyama et al., 2012, Meakin et al., 2014a). The methods required for this procedure have been extensively described elsewhere (Javaheri et al., 2019a, Melville et al., 2015) and will not be repeated here. The standard in vivo loading protocol described here is intended to generate lamellar bone formation in 16-week-old C57BL/6 mice of both genders.

An additional confounding variable is the site of the bone in which functional adaptation is assessed. While seemingly paradoxical, applying mechanical loading axially through the mouse tibia is now known to cause bone gain in a site-specific manner (Carrieroa et al., 2018, Sugiyama et al., 2008). The proximal tibia shows a much greater increase in cortical bone mass than the distal tibia following two weeks of tri-weekly axial loading (Sugiyama et al., 2012). While the biological mechanisms underlying this site-specificity are unknown, engineeringinspired hypotheses such as the effect of greater proximal curvature have been proposed to explain this site-specificity (Dodge et al., 2012). What is even more perplexing is that "systemic" interventions such as deletion of osteogenic or anti-osteogenic genes also regionally alter cortical bone mass. One of the first studies to describe genetically-determined site-specificity investigated the effect of ER $\alpha$ deletion in osteoclasts on femoral bone mass (Nakamura et al., 2007). Measurement of femoral bone mineral density in 20 equal segments along the length of the femur using dual X-ray absorptiometry identified genotype-related differences proximally, but not distally. The time and resources required to scan an entire mouse bone initially limited the analysis of multiple sites along each bone using micro-computed tomography $(\mu \mathrm{CT})$. As $\mu \mathrm{CT}$ scanning became faster and more accessible, various groups reported changes in bone mass in response to loading as well as systemic interventions at multiple sites along the length of the bone (Sugiyama et al., 2008, de Souza et al., 2005, Javaheri et al., 2018). We further extended this multi-site analysis approach, initially to provide a global picture of compartmentalised 
cortical bone phenotypes caused by Prkca deletion (Galea et al., 2014). This global gene deletion produced very regional in-growth of trabecular-like bone into the endosteal cavity at specific sites of long bones.

Problems faced early-on in applying site-specific analyses of bone mass included requirement for extensive computing power to analyse each $\mu \mathrm{CT}$ slice through an adult mouse bone (typically $\sim 2,000$ slices at $10 \mu \mathrm{m}$ voxel sizes), needing to exclude the fibula from studies focused on the tibia, and difficulties in aligning each bone at a meaningful landmark. To address these we developed a simple Site Specificity workflow, which was validated and reported as a sensitive, rapid screening tool (Galea et al., 2015). Site Specificity follows a very simple workflow with open source MATLAB-executed code. Similar workflows have also been described by others (Javaheri et al., 2019b). Application of Site Specificity allows quantitative discrimination between regional and global changes in cortical mass in response to changes in loading, ageing, genetic mutations and hormonal treatment (Galea et al., 2015, Meakin et al., 2017, Orriss et al., 2018).

In this chapter we detail the methods involved in axially loading the mouse tibia, imaging the tibia using $\mu \mathrm{CT}$ analysis, and screening for site-specific versus global changes in cortical bone mass. 


\section{Materials}

3.1 Strain gauging and in vivo axial tibial loading

a) Strain gauge Make, Model, Source, Gauge Factor, ideally Cat number

b) Glass board, Source, Cat number

c) M-Flux, Source, Cat number

3.2 Strain gauging and in vivo axial tibial loading

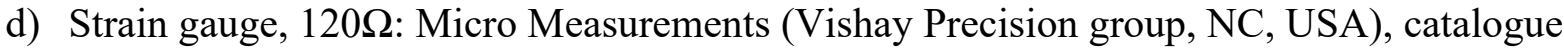
number EA-06-031DE-120

e) PCT-3M gauge installation tape, Micro Measurements

f) M-Flux, Micro Measurements

g) Single conductor wire 134 AWP, Micro Measurements

h) M-Bond 200 adhesive and Catalyst, Micro Measurements

i) Tin lead soldering wirer $60 / 400.8 \mathrm{~mm}$

j) Soldering station

k) Multimeter, e.g. Digital multimeter, auto-range, VWR (Lutterworth, UK), catalogue number 620-1920

1) Dissection microscope with extra light

m) Glass plate

n) Cotton swabs

o) Scalpels and forceps

p) Isopropanol or $70 \%$ ethanol

q) Polyeurythane spray (purchased from local hardware stores)

3.3 Ex vivo $\mu \mathrm{CT}$ imaging

a) There are several $\mu \mathrm{CT}$ instruments. Methods and settings described in section 3.2 Ex vivo $\mu \mathrm{CT}$ imaging below is optimised for the use of an 1172 model, Bruker microCT (Aartselaar, Belgium).

b) BMD calibration phantoms, 0.25 and $0.75 \mathrm{~g} / \mathrm{cm}^{3}$, Bruker microCT (Aartselaar, Belgium)

3.4 Site Specificity and statistical analysis

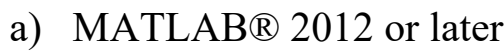

b) FIJI (NIH, ImageJ) with BoneJ installed

c) IBM SPSS Statistics

\section{Methods}

\subsection{Strain gauging and in vivo axial tibial loading}

Pre-gauging is performed to ensure that matched osteogenic strains are engendered by the loads applied to each experimental group. Pre-gauging should be performed before the loading 
experiment on a subset of animals from the same group to be used in the loading experiment. When multiple groups are to be compared, the load:strain relationship should be calculated for each group (Note 1). Protocols related to anaesthetising and working with live mice are beyond the scope of this chapter.

\subsection{Preparation of the gauges}

1. Place the gauge on the glass board (shining side up, Figure 1)

2. Secure one of the long edges of the gauge to the board with adhesive masking tape

3. Cut three sides of the gauge as shown in Figure 1.

4. Lightly scratch the terminals with the blade to improve solder adherence

5. Apply a drop of M-Flux to each terminal

6. Apply solder to each terminal

7. Prepare two lengths of wires to be soldered onto the strain gauge:

i. Trim wire lengths to connect the gauge from the mouse's leg to the strain gauge unit

ii. Remove the insulation from the end of the wires

iii. Dip the ends in M-Flux

iv. Apply solder to the ends

8. Solder the wires to the terminals of the gauge (Figure 2)

9. Test the soldered gauge with a multimeter to ensure the resistance remains within the tolerance of the gauge $(120 \pm 0.2 \Omega$ is perfect; $118-121 \Omega$ should work, below 120 is better than above) and then tape the wires together

10. Cut the gauge, loosening it from the tape (line 4, Figure 1)

11. Spray the gauge with polyeurythane

12. Test the gauge again with the multimeter

4.2 Attach the strain gauge to the tibia of a recently euthanized mouse to pre-gauge (Figure 3)

i. Euthanize the mouse

ii. Locally dissect the area of the right tibia where the strain gauge should be applied

iii. Wipe the bone with a cotton swab dipped in EtOH or isopropanol to degrease the bone and facilitate attachment of the gauge

4.3 Attachment of the gauge to the mouse tibia

i. Place a drop of catalyst and a drop of glue on a piece of foil

ii. Dip the gauge in catalyst

iii. Immediately dip the gauge in glue and touch a clean bit of the surface to remove excess glue. Too much glue will disable the function of the gauge

iv. Hold the gauge steady on the bone with forceps to attach it to the bone. See the images below for the correct site. The centre of the gauge should be where the tibia is the widest. The upper part of the gauge should be positioned where there is an indention at the medial side.

v. Test the gauge with a multimeter

vi. Secure with polyeurythane (on gauge \& bone if stored cold in PBS before use) 
4.4 Place the limb to be pre-gauged in your loading device and subject it to multiple, graded loads, recording the strain gauge resistance at each load. A typical pre-gauging waveform is described below:

$\begin{array}{rlrl}\text { i. } & \text { Ramp } & \text { Load } & 0.5 \mathrm{~N} / \mathrm{s} \text { to }-0.5 \mathrm{~N} \text { (Pre-load) } \\ \text { ii. } & \text { Dwell } & \text { Load } & 7 \mathrm{~s} \\ \text { iii. } & \text { Ramp } & \text { Load } & 460 \mathrm{~N} / \mathrm{s} \text { to }-6 \mathrm{~N} \text { (Peak compressive load) } \\ \text { iv. } & \text { Dwell } & \text { Load } & 5 \mathrm{~s} \\ \text { v. } & \text { Ramp } & \text { Load } & 460 \mathrm{~N} / \mathrm{s} \text { to }-0.5 \mathrm{~N} \\ \text { vi. } & \text { Dwell } & \text { Load } \quad 2 \mathrm{~s} \\ \text { vii. } & \text { Repeat iii to vi three times, recording the resistance value achieved each time. } \\ \text { viii. } & \text { Repeat iii to vii with increasing peak loads in Step 3. } \\ \text { ix. } & \text { Ramp } \quad \text { Displace } 1.9 \mathrm{~mm} / \mathrm{s} \text { to } 0.8 \mathrm{~mm} \text { (Unload) }\end{array}$

Test each load at least three times on each bone. The resulting load versus gauge resistance plot can then be used to generate load:strain graphs by using the gauge factor to convert resistance values into strain values.

4.5 Axially load the tibia of anaesthetised mice.

Once you know what loads need to be applied experimentally, place an anaesthetised mouse in the loading device so that the knee is fixed in the upper cup, and the foot is fixed in the lower cup. Make sure that the foot and knee are aligned so that the joint is loaded axially (Note 2). The sequence below describes a standard rest-inserted loading program applying 40 cycles or $11 \mathrm{~N}$ compressive load.

$\begin{array}{rllll}\text { i. } & \text { Ramp } & \text { Load } & 0.5 \mathrm{~N} / \mathrm{seconds} \text { to }-0.5 \mathrm{~N} & \text { (Pre-load) } \\ \text { ii. } & \text { Dwell } & \text { Load } & 2 \mathrm{sec} & \\ \text { iii. } & \text { Ramp } & \text { Load } & 393 \mathrm{~N} / \mathrm{second} \text { to }-11 \mathrm{~N} & \text { (Peak load, Note 3) } \\ \text { iv. } & \text { Dwell } & \text { Load } & 0.05 \mathrm{sec} & \\ \text { v. } & \text { Ramp } & \text { Load } & 393 \mathrm{~N} / \mathrm{sec} \text { ) } & \\ \text { vi. } & \text { Dwell } & \text { Load } & 10.5 \mathrm{Nec} & \\ \text { vii. } & \text { Repeat } & \text { III-VI } & 39 \mathrm{repeats} & \text { (Rest period) } \\ \text { viii. } & \text { Ramp } & \text { Displace } & 1.9 \mathrm{~mm} / \mathrm{second} \text { to } 1.9 \mathrm{~mm} & \text { (Repetitions) } \\ \text { (Unload) }\end{array}$

\subsection{Ex vivo $\mu \mathrm{CT}$ imaging}

3.2.1 Dissect the left (control) and right (exogenously loaded) tibia.

i. Euthanize the mouse using an ethically approved method which the experimenter is competent and confident performing.

ii. Using sharp-tipped scissors, make a skin incision over the femur. The skin can then be manually pulled distally over the calcaneus (Note 3 ).

iii. Proximally, flex the knee (stifle) and insert the sharp tip of a 10A scalpel laterally to medially through the popliteus to sever muscle and tendon attachments. Similarly, cut through the straight patellar ligament and collateral ligaments on either side of the knee. This should destabilise the joint, allowing you to insert the scalpel into the joint to cut the collateral ligaments and disarticulate the femur from the tibia (Note 4). 
iv. Distally, flex the ankle (hock) and cut through the intertarsal joints. It is not necessary to disarticulate the talus from the tibia and doing so can occasionally damage the medial malleolus and artefactually shorten the tibia, affecting bone measurement.

\subsubsection{Fix and dehydrate the tibia}

i. $\quad$ Fix the bone and muscle in chilled 4\% PFA for 2 days.

ii. Dehydrate the tibia and muscle in $70 \%$ ethanol (Note 5).

3.2.3 $\mu \mathrm{CT}$ scan each bone. Methods and settings described here may need to be adapted to the specific $\mu \mathrm{CT}$ scanner available following the manufacturers' instructions.

i. Prepare the bone by rolling the bone in non-PVC cling film and place in the container (i.e. a straw). Attach the straw to the $\mu \mathrm{CT}$ stage stand before screwing it into the scanner. If the bone can be scanned dry, make sure the bone has dried out for $\sim 10$ minutes before the scan. Evaporation during the scan can alter the density values. If the bone needs to remain moist, then it can be scanned in $70 \%$ ethanol within a cut-down $1 \mathrm{~mL}$ syringe using syringe stoppers above and below the bone to keep the bone stable and avoid evaporation.

ii. Select the parameters that best suit your bone. For mouse bones, we use a 0.5 $\mathrm{mm}$ Aluminum filter to reduce beam hardening. Beam hardening is what happens when the bone preferentially absorbs low energy photons and results in a dark looking surface. The filter will decrease the low energy output and improve the image. The whole tibiae and surrounding muscles are typically imaged with a voxel size of $4.8 \mu \mathrm{m}(110 \mu \mathrm{m} 3)$. The applied x-ray voltage is $49-50$ $\mathrm{kV}$, current of $200 \mathrm{~mA}$, with $0.5 \mathrm{~mm}$ aluminum filtration. Scans are obtained over 180 degrees with a 0.6 -degree rotation step. The images can be reconstructed and binarised with global thresholding (values: 1.000-1.160) using the NRecon Bruker software.

iii. If the entire bone does not fit on one scanning run, an 'oversize scan' may be needed to scan larger bones, which can then be merged digitally in postprocessing to generate a single bone series.

iv. Once scanning is complete, replace bone in $70 \%$ ethanol solution and proceed with processing for additional tests (Note 6).

3.2.4 Reconstruct the RAW 2D radiographic images generated from the CT scanner following the manufacturer's instructions. This should provide reconstructed *.bmp files representing cross-sections through the bone, which used by Site Specificty (Note 7).

\subsection{Site Specificity and statistical analysis}

3.3.1 Place the reconstructed cross-section $\mu \mathrm{CT}$ images for each bone in a single folder, henceforth the "Inpath". Ensure there are no blank ("spacer") slices in the folder as bone length is calculated from the number of slices in this folder.

3.3.2 Create a local copy of the SiteSpecificityV2.m script. This can be downloaded from https://www.researchgate.net/publication/295858230_SiteSpecificityV2 and is available with the original manuscript (Galea et al., 2015). 
3.3.3 Open MATLAB ${ }^{\circledR}$, direct it to the directory containing SiteSpecificityV2.m and open the script for editing.

3.3.4 Modify the Inpath line (line 13) to the folder containing the bone to be analysed (Note 4). For example, change this line to read:

$$
\text { inpath }=\text { 'C: } \backslash \text { Site specificity } \backslash \text { Example }\rfloor^{\prime}
$$

3.3.5 Save the script file and run it. The script will create an "Output" folder within the Inpath. It will count the number of images of the folder and identify the images corresponding to each $1 \%$ site along the bone's length (Note 8). The corresponding 100 images each undergo the following processing (Figure 2a, b):

i. Locally adaptive binarisation to identify the bone and exclude soft tissue.

ii. Identification of the largest continuous object (the tibia) and exclusion of smaller objects (the fibula and trabecular bone).

iii. Quantification of the binarised area. This is exported as "Bone Area" and corresponds to Cortical Area (Ct.Ar) in conventional $\mu \mathrm{CT}$ analysis. The output report will display this as pixels ${ }^{2}$ and should be converted to $\mathrm{mm}^{2}$ using the voxel size known from the $\mu \mathrm{CT}$ reconstruction settings.

iv. Quantification of empty space within the binarised area (Note 9). This is reported as "Marrow Area" (i.e. Ma.Ar) in pixels ${ }^{2}$.

v. The perimeter of the binarised area is also provided. If required, Bone Area and Marrow Area can be summer to calculate Total Tissue Area (Tt.Ar).

3.3.6 The Output folder will now contain 100 images saved as .gif files corresponding to each $1 \%$ site along the bone's length, .txt result files with the cross-sectional measurements at each site, and a single .csv file amalgamating the results (Note 10). The .gif files retain the same pixel dimensions as the original image but are of much smaller size such that they can be easily processed in additional software if needed.

3.3.7 To quantify parameters beyond those directly calculated by Site Specificity, drag and drop the Output folder into Fiji. This will open the sub-sampled cross-section images as a stack. Additional parameters, such as moments of inertia and cross-sectional thickness, can now be calculated using the BoneJ plugin (Doube et al., 2010).

3.3.8 Iteratively repeat the process until all bones have been analysed. The resulting data can now be graphed as in Figure $4 \mathrm{c}$ to confirm successful analysis. If using Site Specificity as a screening tool with a small number of bones, you can stop at this point. The following steps describe statistical comparison between treatment groups using the mixed model procedure in SPSS.

i. Mixed models are used to test the effect of random effects (e.g. cage number), fixed effects (e.g. loading) and fixed covariates (e.g. \% site along the bone's length). Strengths and limitations of mixed models are described elsewhere (e.g. (Yang et al., 2014)).

ii. Set up a datasheet with the following headings: Animal ID, Site (\% bone length), and Treatment (e.g. loading, drug, genotype). Enter all data in a single list under each of these headings. Set the appropriate variable types in the SPSS "Variable view" tab.

iii. In SPSS, select the linear mixed models option. Specify the Animal ID as the "subject", Site as the "repeated measure" (Note 11) and click continue. Set up 
your model as needed on the next screen (see the SPSS help function on your version of the software if you are not familiar with how to do this).

iv. An important outcome of Site Specificity analysis is quantification of whether the response to treatment is significantly different between different sites. This is shown by a significant Site by Treatment interaction (indicates the response to treatment is significantly different between different sites).

v. To request a direct comparison between different sites with a Bonferroni posthoc comparison, click "Paste" to obtain the model syntax and add the following text at the end of the syntax before the full stop:

/EMMEANS=TABLES(Treatment*Site) COMPARE(Treatment) ADJ(Bonferroni).

vi. Post-hoc comparisons are generated in a table under the sub-heading "Pairwise Comparisons" (Notes 12, 13).

vii. The same syntax can now be re-run for other bone parameters in the same experiment.

\section{Notes}

1. Be careful when applying a treatment/genetic modification which alters bone structure before starting a loading experiment. If the same load is applied to bones with different mass and architecture, different levels of osteogenic strain will be engendered.

2. If the tibia is not place directly vertical between the upper and lower cups, the knee will be forced forward or back, which is likely to rupture the cruciate ligaments. If this happens in an anesthetised mouse, cull the mouse before it wakes up.

3. Most materials testing devices will avoid exceeding the specified load and, at rapid loading rates with short dwell times, often fail to achieve the desired peak load. You may need to set a set a slightly higher programmed peak load in order to achieve the desired force (e.g. set a peak load of $-11.2 \mathrm{~N}$ to achieve a load of $-11 \mathrm{~N}$ ).

4. It is usually easy to evert and unroll mouse skin off the tibia up to the calcaneus, but harder to fully remove it. There is no need to pull it further. If the tibia is to be scanned and analysed, ensure the femur is grasped instead to avoid fracturing the fibula. The fibula is itself a loading-responsive bone which can be analysed separately.

5. Disarticulating the tibia and femur can be tricky in some mice. It is essential to obtain the entire tibia to direct the analysis at each percent of the bone's length. If the experimenter finds this difficult at first, cut through the distal femur instead. Handling tissues with wet gloves on wet tissue paper sometimes helps and a dissection microscope can be used if needed.

6. The same bone can be used for histology and histomorphometry end points as well as $\mu \mathrm{CT}$ scanning. For histology, the bone should be fixed (e.g. in paraformaldehyde) prior to dehydration. It is often helpful to trim away some of the overlying muscles to aid fixative penetration but be careful not to break the fibula.

7. SiteSpecifictyV2.m is intended to analyse .bmp image files. If a different file type is used, this can be changed in line 26 ("d $=\operatorname{dir}([$ inpath, '*.bmp']);").

8. The level of sub-sampling is set to 100 images, with each image corresponding to a $1 \%$ site along the bone's length by default. This sub-sampling can be changed in line 31 ("num_samples = 100;"). 
9. Large pores and blood vessels which breach the cortex in a single slice effectively cause the marrow area to become continuous with the background, producing a small or zero Ma.Ar measurement which should be excluded from subsequent analyses. Straight transcortical breaches in a single slice are rare in the cortex of young adult mice and the Ct.Ar measurement primarily used to screen bone mass is unaffected. Workarounds are therefore not directly implemented in Site Specificity, but if these breaches are problematic (e.g. genetic model with very low bone mass), the sub-sampled binarised images saved in the Output folder can easily be reanalysed in conventional $\mu \mathrm{CT}$ analysis software (e.g. CtAN, Bruker) implementing a shrink-wrap function. The small number and size of sub-sampled images means these can be batch-processed very quickly.

10. If the extremes of the bone have very faint signal which is of soft-tissue equivalence, such that they binarise to produce a black image, that slice will be excluded from the analysis. The total number of output images and values will therefore be less than 100 . Additionally, the proximal and distal extremes of the bone contain trabecular bone which cannot be analysed using Site Specificity. We therefore exclude the proximal and distal $10-15 \%$ of the tibia from our analysis. This may not be necessary when analysing less trabecular bone such as the mouse ulna.

11. The structure of the model used will vary depending on the endpoint. When testing whether an intervention enhances or diminishes the response to loading, it may be more appropriate to calculate the percentage difference between loaded and control limbs for each mouse and use this loading response as the dependant variable. This is especially true if the intervention itself changes baseline bone mass (see Strain Gauging methods above).

12. Displaying regions of significant differences between treatment groups across multiple sites can be challenging. We and others have adopted various methods to show this in previous publications.

13. Calculating the statistical power to identify differences as statistically significant using a complex mixed model approach is challenging. It is possible to simulate changes in bone mass by resizing the Output images in Fiji by a known percentage. This provides an indication of the proportion of sites at which that percentage change would be detected as statistically significant. In our initial validation of this analysis method (Galea et al., 2015), a 10\% change in Ct.Ar was detected as significant at $98.8 \%$ of sites analysed. 


\section{References}

BERGSTROM, I., ISAKSSON, H., KOSKELA, A., TUUKKANEN, J., OHLSSON, C., ANDERSSON, G. \& WINDAHL, S. H. 2018. Prednisolone treatment reduces the osteogenic effects of loading in mice. Bone, 112, 10-18.

CARRIEROA, A., PEREIRAB, A. F., WILSON, A. J., CASTAGNO, S., JAVAHERI, B., PITSILLIDES, A. A., MARENZANA, M. \& SHEFELBINE, S. J. 2018. Spatial relationship between bone formation and mechanical stimulus within cortical bone: Combining 3D fluorochrome mapping and poroelastic finite element modelling. Bone Rep, 8, 72-80.

DE SOUZA, R. L., PITSILliDES, A. A., LANYON, L. E., SKERRY, T. M. \& CHENU, C. 2005. Sympathetic nervous system does not mediate the load-induced cortical new bone formation. J Bone Miner Res, 20, 2159-68.

DODGE, T., WANIS, M., AYOUB, R., ZHAO, L., WATTS, N. B., BHATTACHARYA, A., AKKUS, O., ROBLING, A. \& YOKOTA, H. 2012. Mechanical loading, damping, and load-driven bone formation in mouse tibiae. Bone, 51, 810-8.

DOUBE, M., KLOSOWSKI, M. M., ARGANDA-CARRERAS, I., CORDELIERES, F. P., DOUGHERTY, R. P., JACKSON, J. S., SCHMID, B., HUTCHINSON, J. R. \& SHEFELBINE, S. J. 2010. BoneJ: Free and extensible bone image analysis in ImageJ. Bone, 47, 1076-9.

GALEA, G. L., HANNUNA, S., MEAKIN, L. B., DELISSER, P. J., LANYON, L. E. \& PRICE, J. S. 2015. Quantification of Alterations in Cortical Bone Geometry Using Site Specificity Software in Mouse models of Aging and the Responses to Ovariectomy and Altered Loading. Front Endocrinol (Lausanne), 6, 52.

GALEA, G. L., MEAKIN, L. B., HARRIS, M. A., DELISSER, P. J., LANYON, L. E., HARRIS, S. E. \& PRICE, J. S. 2017. Old age and the associated impairment of bones' adaptation to loading are associated with transcriptomic changes in cellular metabolism, cell-matrix interactions and the cell cycle. Gene, 599, 36-52.

GALEA, G. L., MEAKIN, L. B., WILLIAMS, C. M., HULIN-CURTIS, S. L., LANYON, L. E., POOLE, A. W. \& PRICE, J. S. 2014. Protein kinase Calpha (PKCalpha) regulates bone architecture and osteoblast activity. J Biol Chem, 289, 25509-22.

HILLAM, R. A. \& SKERRY, T. M. 1995. Inhibition of bone resorption and stimulation of formation by mechanical loading of the modeling rat ulna in vivo. J Bone Miner Res, 10, 683-9.

JAVAHERI, B., BRAVENBOER, N., BAKKER, A. D., VAN DER VEEN, A., DE SOUZA, R. L., SAXON, L. \& PITSILLIDES, A. A. 2019a. In Vivo Models of Mechanical Loading. Methods Mol Biol, 1914, 369-390.

JAVAHERI, B., CARRIERO, A., WOOD, M., DE SOUZA, R., LEE, P. D., SHEFELBINE, S. \& PITSILLIDES, A. A. 2018. Transient peak-strain matching partially recovers the ageimpaired mechanoadaptive cortical bone response. Sci Rep, 8, 6636.

JAVAHERI, B., HERBERT, E., HOPKINSON, M., AL-JAZZAR, A. \& PITSILLIDES, A. A. 2019b. Sost Haploinsufficiency Provokes Peracute Lethal Cardiac Tamponade without Rescuing the Osteopenia in a Mouse Model of Excess Glucocorticoids. Am J Pathol, 189, 753-761.

LIONIKAITE, V., HENNING, P., DREVINGE, C., SHAH, F. A., PALMQUIST, A., WIKSTROM, P., WINDAHL, S. H. \& LERNER, U. H. 2019. Vitamin A decreases the 
anabolic bone response to mechanical loading by suppressing bone formation. FASEB J, 33, 5237-5247.

MEAKIN, L. B., GALEA, G. L., SUGIYAMA, T., LANYON, L. E. \& PRICE, J. S. 2014a. Agerelated impairment of bones' adaptive response to loading in mice is associated with sexrelated deficiencies in osteoblasts but no change in osteocytes. J Bone Miner Res, 29, 1859-71.

MEAKIN, L. B., PRICE, J. S. \& LANYON, L. E. 2014b. The Contribution of Experimental in vivo Models to Understanding the Mechanisms of Adaptation to Mechanical Loading in Bone. Front Endocrinol (Lausanne), 5, 154.

MEAKIN, L. B., TODD, H., DELISSER, P. J., GALEA, G. L., MOUSTAFA, A., LANYON, L. E., WINDAHL, S. H. \& PRICE, J. S. 2017. Parathyroid hormone's enhancement of bones' osteogenic response to loading is affected by ageing in a dose- and time-dependent manner. Bone, 98, 59-67.

MELVILLE, K. M., ROBLING, A. G. \& VAN DER MEULEN, M. C. 2015. In vivo axial loading of the mouse tibia. Methods Mol Biol, 1226, 99-115.

MOUSTAFA, A., SUGIYAMA, T., PRASAD, J., ZAMAN, G., GROSS, T. S., LANYON, L. E. \& PRICE, J. S. 2012. Mechanical loading-related changes in osteocyte sclerostin expression in mice are more closely associated with the subsequent osteogenic response than the peak strains engendered. Osteoporos Int, 23, 1225-34.

NAKAMURA, T., IMAI, Y., MATSUMOTO, T., SATO, S., TAKEUCHI, K., IGARASHI, K., HARADA, Y., AZUMA, Y., KRUST, A., YAMAMOTO, Y., NISHINA, H., TAKEDA, S., TAKAYANAGI, H., METZGER, D., KANNO, J., TAKAOKA, K., MARTIN, T. J., CHAMBON, P. \& KATO, S. 2007. Estrogen prevents bone loss via estrogen receptor alpha and induction of Fas ligand in osteoclasts. Cell, 130, 811-23.

ORRISS, I. R., LANHAM, S., SAVERY, D., GREENE, N. D. E., STANIER, P., OREFFO, R., COPP, A. J. \& GALEA, G. L. 2018. Spina bifida-predisposing heterozygous mutations in Planar Cell Polarity genes and Zic2 reduce bone mass in young mice. Sci Rep, 8, 3325.

ROBLING, A. G., NIZIOLEK, P. J., BALDRIDGE, L. A., CONDON, K. W., ALLEN, M. R., ALAM, I., MANTILA, S. M., GLUHAK-HEINRICH, J., BELLIDO, T. M., HARRIS, S. E. \& TURNER, C. H. 2008. Mechanical stimulation of bone in vivo reduces osteocyte expression of Sost/sclerostin. J Biol Chem, 283, 5866-75.

SKERRY, T. M. 2006. One mechanostat or many? Modifications of the site-specific response of bone to mechanical loading by nature and nurture. J Musculoskelet Neuronal Interact, 6, 122-7.

SKERRY, T. M., BITENSKY, L., CHAYEN, J. \& LANYON, L. E. 1989. Early strain-related changes in enzyme activity in osteocytes following bone loading in vivo. $J$ Bone Miner Res, 4, 783-8.

SUGIYAMA, T., MEAKIN, L. B., BROWNE, W. J., GALEA, G. L., PRICE, J. S. \& LANYON, L. E. 2012. Bones' adaptive response to mechanical loading is essentially linear between the low strains associated with disuse and the high strains associated with the lamellar/woven bone transition. J Bone Miner Res, 27, 1784-93.

SUGIYAMA, T., SAXON, L. K., ZAMAN, G., MOUSTAFA, A., SUNTERS, A., PRICE, J. S. \& LANYON, L. E. 2008. Mechanical loading enhances the anabolic effects of intermittent parathyroid hormone (1-34) on trabecular and cortical bone in mice. Bone, $43,238-48$. 
SVENSSON, J., WINDAHL, S. H., SAXON, L., SJOGREN, K., KOSKELA, A., TUUKKANEN, J. \& OHLSSON, C. 2016. Liver-derived IGF-I regulates cortical bone mass but is dispensable for the osteogenic response to mechanical loading in female mice. Am J Physiol Endocrinol Metab, 311, E138-44.

YANG, J., ZAITLEN, N. A., GODDARD, M. E., VISSCHER, P. M. \& PRICE, A. L. 2014. Advantages and pitfalls in the application of mixed-model association methods. Nat Genet, 46, 100-6. 


\section{Figures and Legends}

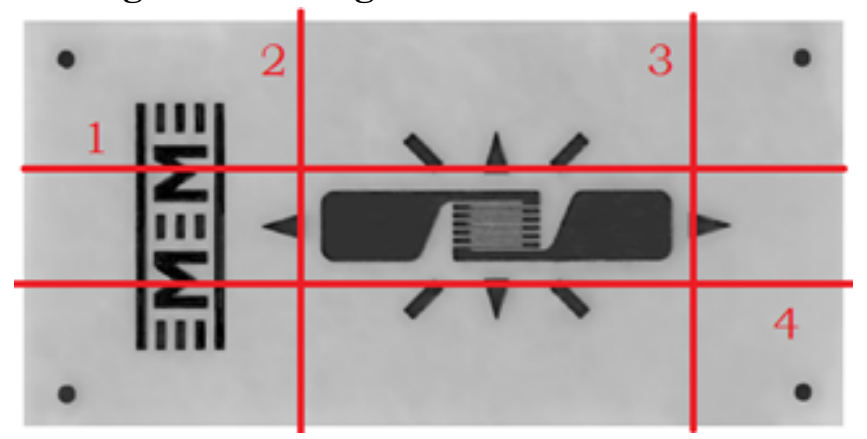

Figure 1. Sites for trimming the strain gauge. The gauge is attached to a glass plate at the bottom of the image. The gauge is then cut with a scalpel in the indicated order 1-4.

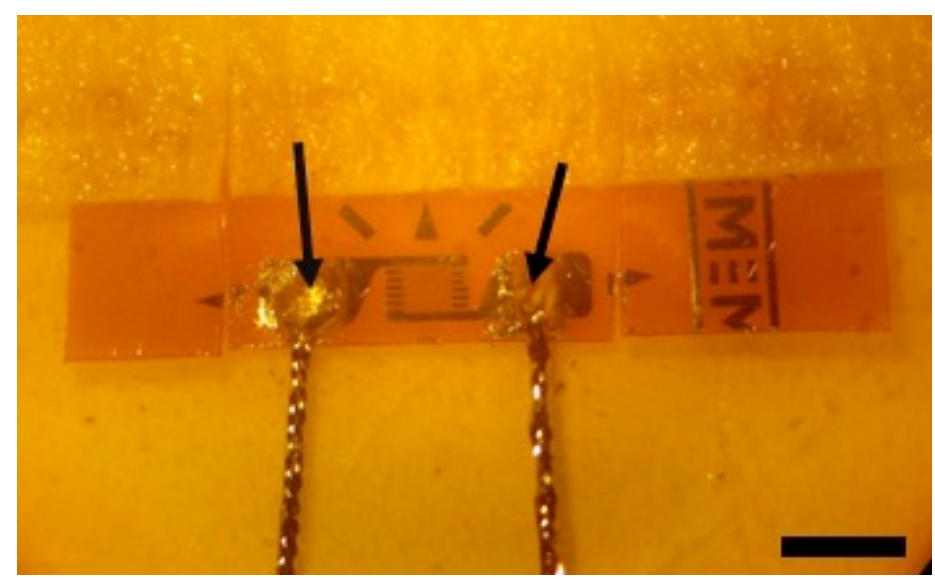

Figure 2. Photomicrograph of strain gauge with the attached wires before the final cut. Solder points (arrows) with wire attached. The side cuts have been made and the top cut is all that remains to be made. The top edge of the gauge is immobilised by masking tape. The scale bar indicates $0.5 \mathrm{~mm}$. 

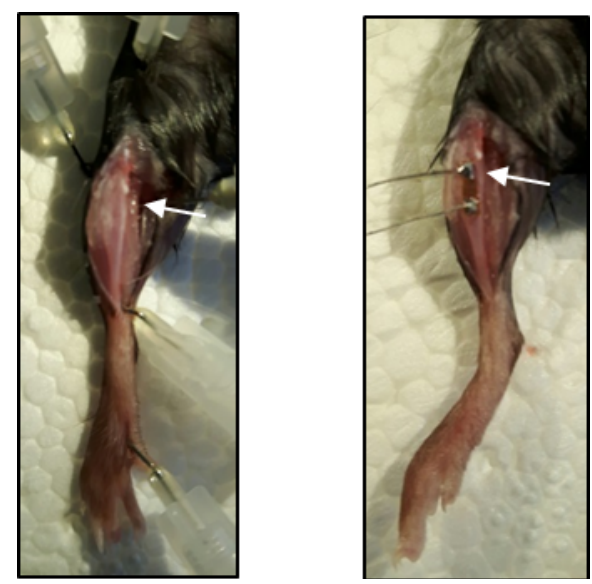

Figure 3. Attachment site of the gauge. The gauge is attached so that the centre of the gauge is located approximately at $37 \%$ of the bone's length proximally. The arrows indicate the where the top of the gauge will be located.

A.

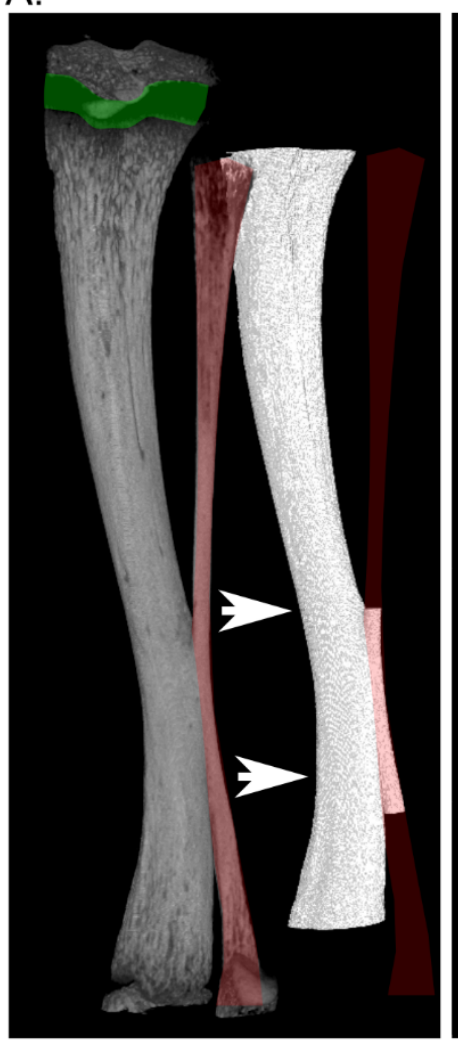

B.

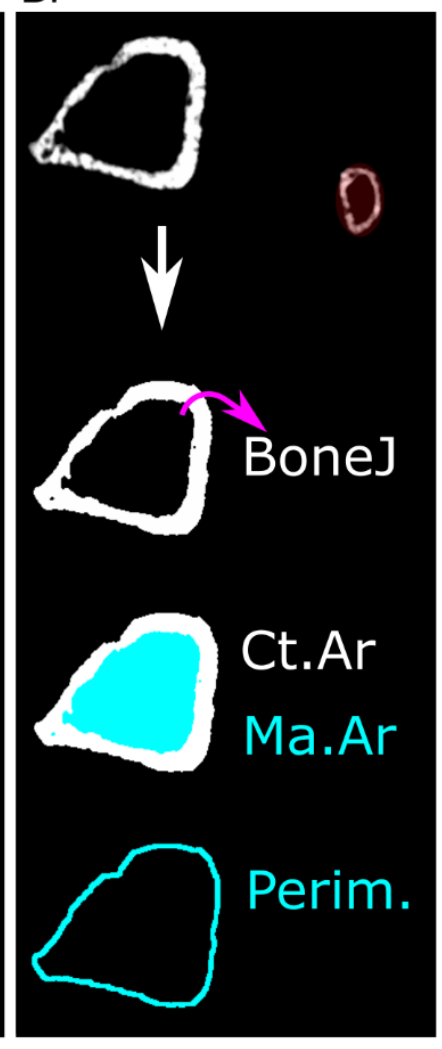

C.

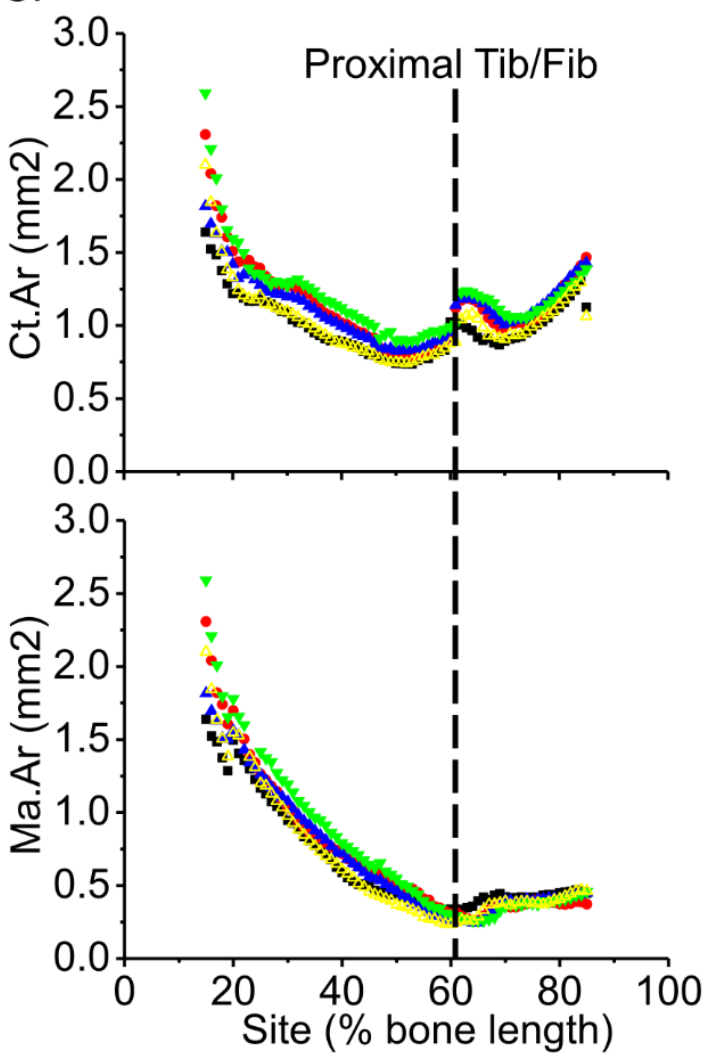

Figure 4: Execution and application of the Site Specificity workflow. A) Schematic representation of Site Specificity analysis applied to the tibia of a 3-week old mouse. The region of the bone analysed by Site Specificity are shown in the binarised reconstruction (right). Parts of the fibula (red highlight) not connected to the tibia are identified and excluded. Images corresponding to each $1 \%$ site along the bone's length are identified. Proximal (including the 
growth plate, green) and distal sites are excluded from the analysis. B) Cross-section through the proximal tibia and fibula (red) at the $20 \%$ site from the proximal end. The binarised tibia images are saved and can be exported into other analysis software such as BoneJ. Cortical area (Ct.Ar), Marrow area (Ma.Ar) and external perimeter are provided as part of the in-built workflow. C) Quantification of Ct.Ar and Ma.Ar in the tibiae of five 3-week old mice showing the expected pattern of cortical bone differences in typical inter-mouse variability. 